www.jmscr.igmpublication.org

Impact Factor 3.79

Index Copernicus Value: 5.88 ISSN (e)-2347-176x ISSN (p) 2455-0450 crossref DOI: _http://dx.doi.org/10.18535/jmscr/v4i02.60

\title{
Cytomorphological Spectrum of Lesions in Liver at Tertiary Care Centre, Haryana \\ (Original Article)
}

Authors

\author{
Dr Gajender Singh ${ }^{1}$, Dr Padam Parmar ${ }^{2}$, Dr Sant Prakash Kataria ${ }^{3}$, \\ Dr Nisha Marwah ${ }^{4}$, Dr Sumiti Gupta ${ }^{5}$, Dr Suman Tomer ${ }^{6}$ \\ ${ }^{1}$ Associate Professor, Department of Pathology, Pt BDS PGIMS, Rohtak, Haryana \\ ${ }^{2}$ Senior resident, Department of Pathology, Pt BDS PGIMS, Rohtak, Haryana \\ ${ }^{3,4,5}$ Professor, Department of Pathology, Pt BDS PGIMS, Rohtak, Haryana \\ ${ }^{6}$ Resident, Department of Pathology, Pt BDS PGIMS, Rohtak, Haryana
}

Email: 1drgajender@rediffmail.com,3drkatariasp@rediffmail.com,3nmarwah6@gmail.com

5uptasumiti30@yahoo.com, ${ }^{5}$ dr.suman117@gmail.com

Corresponding Author

Dr Padam Parmar

Department of Pathology, Pt BDS PGIMS, Rohtak, Haryana 124001 (India)

Email: drpadamparmar@gmail.com,. No.: 09355149508

\begin{abstract}
Introduction: Benign and malignant hepatic lesions need timely and accurate diagnosis for proper management. Fine needle aspiration cytology (FNAC) under ultrasonograhy guidance is primary investigation for liver lesion specially in deep seated lesions as it is minimally invasive, precise and reproducible investigation.

Material and methods: A total of 95 cases suspected for liver lesions were subjected to FNAC over a period of one year. Coagulation parameters along with complete blood counts were done on all the patients. The cytological aspirates were obtained using a 22 gauze spinal needle under ultrasound evaluation. Air dried and wet fixed (95\% alcohol) smears were prepared for May-Grunwald Giemsa and Papanicolaou or Hematoxylin and Eosin stain respectively. Special stains were used wherever necessary. Diagnosis was made on the basis of cytomorphological features of the lesion.

Results: Patients age ranged from 15-90 years with maximum number of patients were in sixth decade. There was male predominance. The cytological diagnosis was made $79 \%$ cases. Cytomorphologically liver lesions were categorized in to malignant (58.95\%), benign (11.58\%), and non-conclusive (21.05\%). Benign lesions included cirrhosis liver (5), fatty liver (4), and pyogenic liver abcess (2). Out of 56 malignant cases, 51 (91.07\%) were of metastatic deposits including adenocarcinoma, renal cell carcinoma, mesenchymal tumor, mucinous and sqamous cell carcinoma. 5 cases (8.93\%) were of primary origin which all are hepatocellular carcinoma (HCC). Primary site for liver metastasis was diagnosed in 33 cases (64.7\%) and unknown in 18 cases (35.3\%). Primary origin from various sites included from gall bladder $(n=10)$, gastrointestinal tumor $(n=6)$, pancreas $(n=6)$, breast $(n=5)$, bronchogenic $(n=3)$, renal cell carcinoma $(n=2)$ and mesenchymal $(n=1)$.

Conclusion: Along with other supportive investigation finding, FNAC have important role in the diagnosis and management of various hepatic lesion in early stage.
\end{abstract}




\section{INTRODUCTION}

At the time of diagnosis, liver malignancy either primary or secondary is usually inoperable due to delay in diagnosis in most of cases. The appropriate management of various hepatic lesions depends on timely and accurate diagnosis. ${ }^{1}$ Ultrasonograhy-guided fine needle aspiration cytology (FNAC) is gaining popularity now a days as it is minimally invasive, precise and reproducible investigation for deep seated lesions. Advantage of FNAC over conventional core biopsy is that it is less invasive with less complication and in most of cases viable and adequate specimen is obtained. ${ }^{3}$ Hemorrhagic diathesis and anticoagulation are few contraindication to this procedure. The differential diagnosis of hepatic mass lesions includes primary liver tumors, metastatic deposits, congenital or acquired cyst, abscesses and granulomas. ${ }^{2}$

The aim of this study was to evaluate the cytomorphological spectrum of various liver lesions and to evaluate the role of FNAC in diagnosis of liver lesions as first line investigation.

\section{MATERIAL AND METHODS}

A total of 95 cases suspected for liver lesions clinically or radiologically were subjected to FNAC over a period of one year from April 2014 to March 2015. Clinical, serological details were obtained from case files. Coagulation parameters along with complete blood counts and liver function tests were done on all the patients. The cytological aspirates were obtained using a 22 gauze spinal needle under ultrasound evaluation and the smears were made as early as possible. Air dried and wet fixed (95\% alcohol) smears were prepared for May-Grunwald Giemsa and Papanicolaou or Hematoxylin and Eosin stain respectively. Special stains like periodic acidSchiff (PAS), reticulin and Ziehl-Neelsen (ZN) were used wherever necessary. Cytomorphological features were studied and a diagnosis was made.

\section{RESULTS}

Patients age ranged from 15-90 years with maximum number of patients were in sixth decade. There were $54(56.84 \%)$ males and 41(43.16\%) females. (Table 1 )

Table 1. Distribution of cases according to age and gender.

\begin{tabular}{|c|c|c|c|}
\hline Age group & Male & Female & Total \\
\hline $15-30$ & 2 & 1 & 3 \\
\hline $31-40$ & 5 & 6 & 11 \\
\hline $41-50$ & 8 & 14 & 22 \\
\hline $51-60$ & 19 & 11 & 30 \\
\hline $61-70$ & 11 & 4 & 15 \\
\hline $71-80$ & 9 & 3 & 12 \\
\hline $81-90$ & 0 & 2 & 2 \\
\hline Total & 54 & 41 & 95 \\
\hline
\end{tabular}

The cytological diagnosis was made in 75 out of 95 cases giving a diagnostic yield of around $79 \%$. Cytomorphologically liver lesions were categorized in to malignant $(56,58.95 \%)$, benign $(11,11.58 \%)$, and non-conclusive $(20,21.05 \%)$. (Table 2)

Table 2: Cytological categorization of liver aspirates

\begin{tabular}{|c|c|c|c|}
\hline S.N & Lesion & No of cases & Percentage (\%) \\
\hline 1. & Malignant & 56 & 58.95 \\
\hline 2. & Benign & 11 & 11.58 \\
\hline 3. & Suspicious of malignancy & 8 & 8.42 \\
\hline 4. & Non-conclusive & 20 & 21.05 \\
\hline & Total & 95 & $100 \%$ \\
\hline
\end{tabular}


Benign lesions included cirrhosis liver (5), fatty liver (4), and pyogenic liver abcess (2). Pyogenic liver abscess mainly showed neutrophils, necrotic debris and benign hepatocytes. No benign neoplasm was reported during the study.

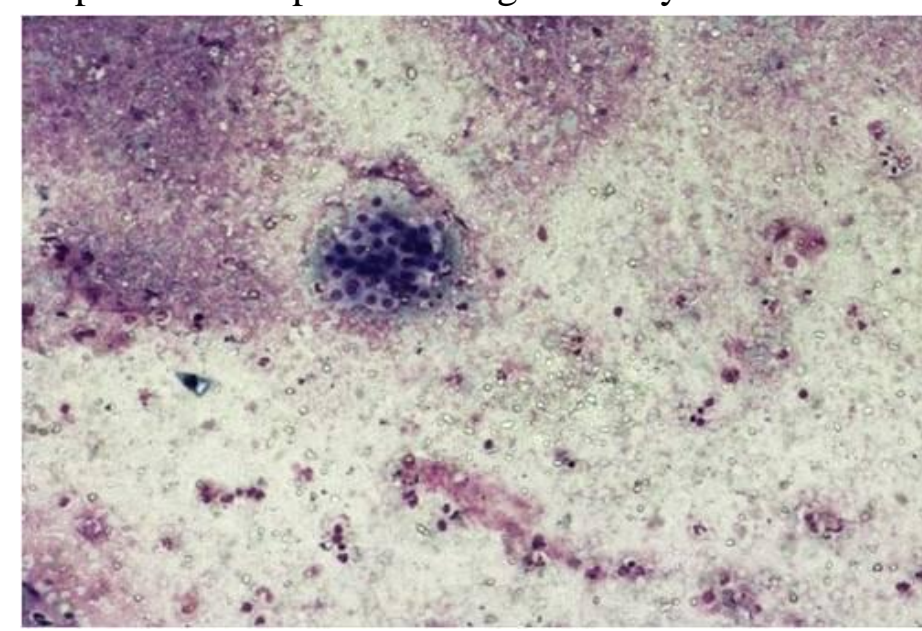

Fig. 1. A case of liver abscess showing a group of benign hepatocytes, inflammatory cells and necrotic debris. (200x)

Out of 56 malignant cases, 51 (91.07\%) were of metastatic deposits including adenocarcinoma, renal cell carcinoma, mesenchymal tumor, mucinous and sqamous cell carcinoma. 5 cases $(8.93 \%)$ were of primary origin which all were hepatocellular carcinoma (HCC).

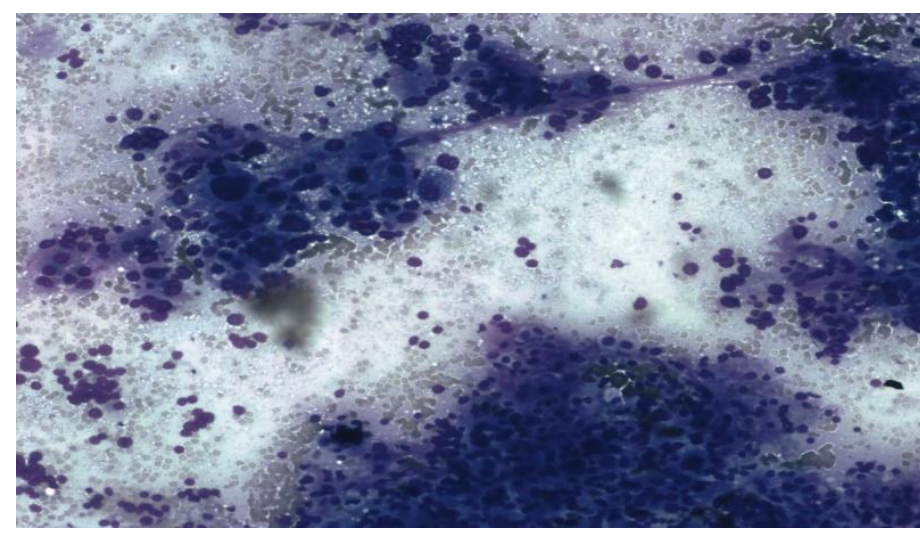

Fig.2. A case of HCC with transgressed blood veseels. $(200 x)$

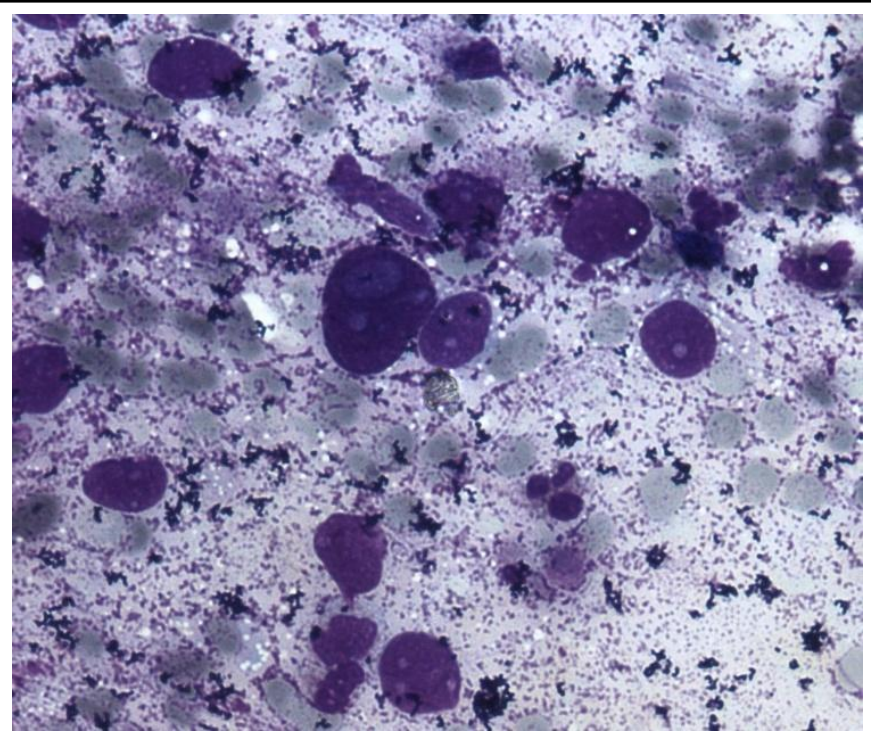

Fig.3. A case of HCC showing malignant cells with enlarged, pleomorphic nuclei with macronucleoli. (400x)

Metastatic deposits constituted poorly differentiated carcinoma 15 (26.79\%), adenocarcinoma 25 (44.65\%), squamous cell carcinoma $4(7.15 \%)$, renal cell carcinoma 2 (3.57\%), mesenchymal tumor $1(1.78 \%)$, mucinous carcinoma $1(1.78 \%)$, round cell tumor $1(1.78 \%)$ and small cell carcinoma $2(3.57 \%)$. (Table 3$)$ 


\section{JMSCR Vol||4||Issue||02||Page 9467-9473||February}

Table 3: Categorisation of malignant cases $(n=56)$

\begin{tabular}{|c|c|c|c|c|c|}
\hline & \multicolumn{3}{|c|}{ Malignant cases } & No of cases & Percentage \\
\hline $\begin{array}{l}\text { Primary } \\
\text { origin }\end{array}$ & \multicolumn{3}{|c|}{ Hepatocellular carcinoma } & 5 & 8.93 \\
\hline \multirow[t]{8}{*}{$\begin{array}{l}\text { Secondary } \\
\text { origin }\end{array}$} & $\begin{array}{l}\text { Poorly differentiated } \\
\text { carcinoma }\end{array}$ & 15 & 26.79 & \multirow{8}{*}{51} & \multirow{8}{*}{91.07} \\
\hline & Adenocarcinoma & 25 & 44.65 & & \\
\hline & $\begin{array}{c}\text { Squamous cell } \\
\text { carcinoma }\end{array}$ & 4 & 7.15 & & \\
\hline & Renal cell carcinoma & 2 & 3.57 & & \\
\hline & Mesenchymal origin & 1 & 1.78 & & \\
\hline & Round cell tumor & 1 & 1.78 & & \\
\hline & Mucinous carcinoma & 1 & 1.78 & & \\
\hline & Small cell carcinoma & 2 & 3.57 & & \\
\hline \multicolumn{4}{|c|}{ Total } & 56 & 100 \\
\hline
\end{tabular}

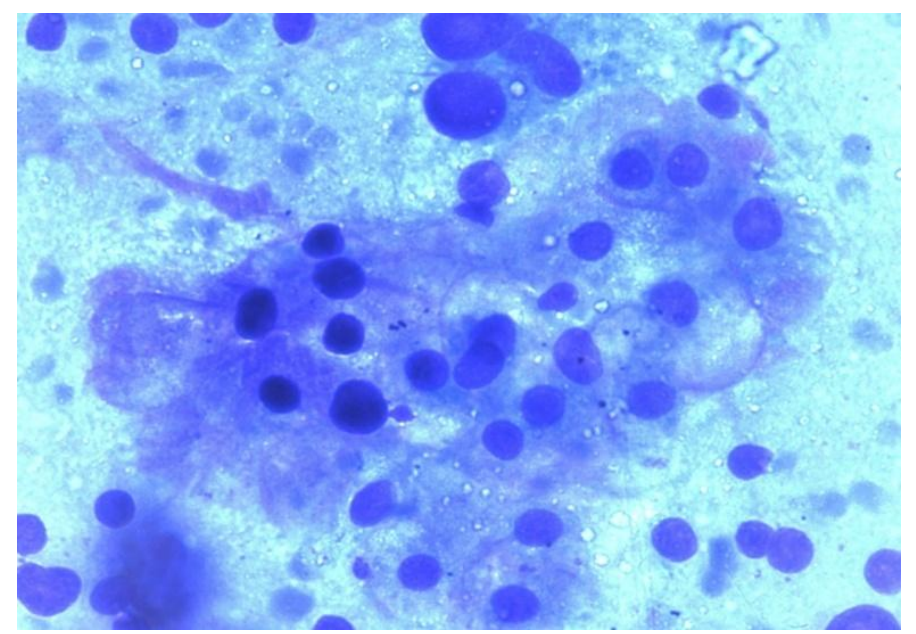

Fig.4. A case of RCC showing atypical cells mainly dispersed singly and in loose clusters having abundant fragile pale eosinophilic cytoplasm.

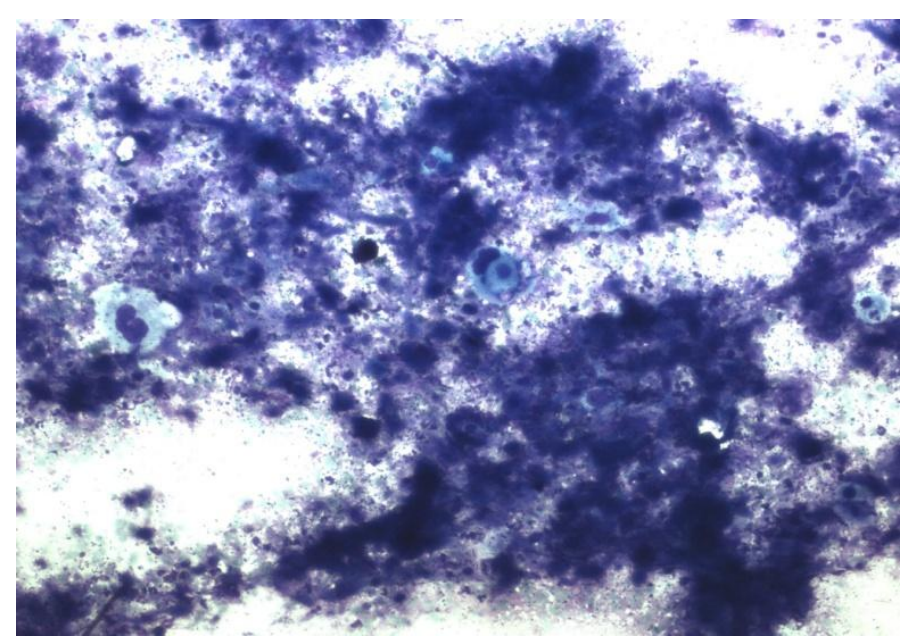

Fig.5. A case of squamous cell carcinoma showing atypical squamous cells having dense opaque cytoplasm in a background of inflammatory cells and necrotic material.

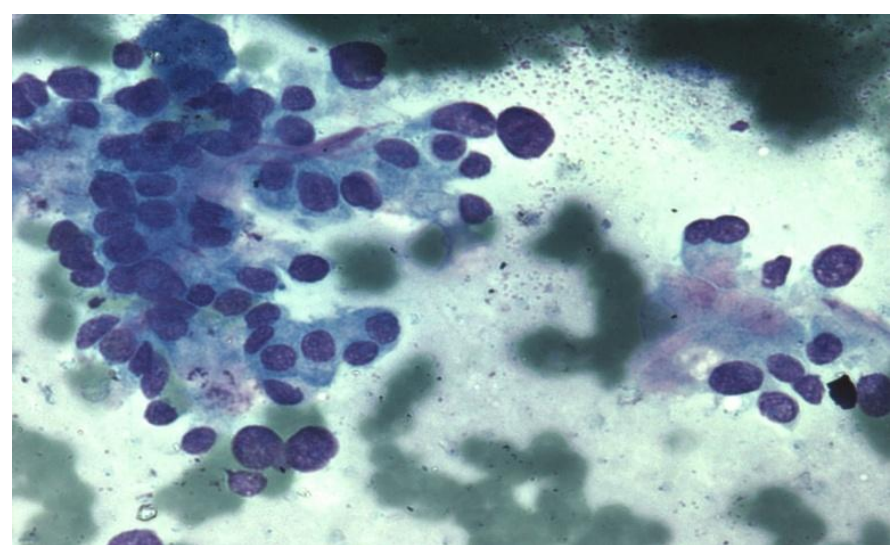

Fig. 6. A case of metastatic deposits from mucinous neoplasm showing groups of cells with pleomorphic nuclei, moderate to abundant pale basophilic cytoplasm against a background of abundant mucin and RBCs.

Clinical history and radiological details were taken to know the primary sites for secondary deposits in liver. Primary site for liver metastasis was diagnosed in 33 cases $(64.7 \%)$ and unknown in 18 cases $(35.3 \%)$. Primary origin included gall bladder (10), gastrointestinal tumor (6), pancreas (6), breast (5), bronchogenic (3), renal cell carcinoma (2) and mesenchymal (1). (table 4) 
Table 4. Primary site for liver metastasis. $(n=51)$

\begin{tabular}{|c|c|c|c|c|}
\hline \multicolumn{3}{|c|}{ LIVER METASTASIS } & No of cases & Percentage \\
\hline \multicolumn{3}{|c|}{ Unknown } & 18 & 35.3 \\
\hline \multicolumn{3}{|c|}{ Known } & \multirow{8}{*}{33} & \multirow{8}{*}{64.7} \\
\hline Gall Bladder & 10 & 19.6 & & \\
\hline GIT & 6 & 11.8 & & \\
\hline Pancreas & 6 & 11.8 & & \\
\hline Breast & 5 & 9.8 & & \\
\hline Bronchogenic & 3 & 5.9 & & \\
\hline $\mathrm{RCC}$ & 2 & 3.9 & & \\
\hline Mesenchymal & 1 & 1.9 & & \\
\hline \multicolumn{3}{|c|}{ Total } & 51 & 100 \\
\hline
\end{tabular}

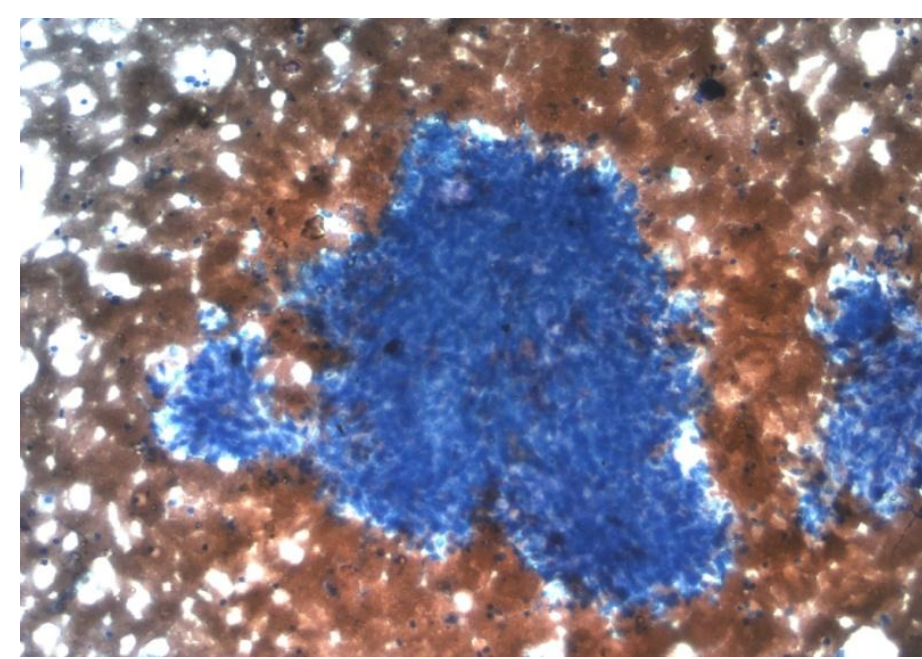

Fig. 7. A case of metastatic deposits from mesenchymal tumor showing atypical oval to spindle cells present in clusters admixed with stromal tissue fragments in a hemorrhagic background.

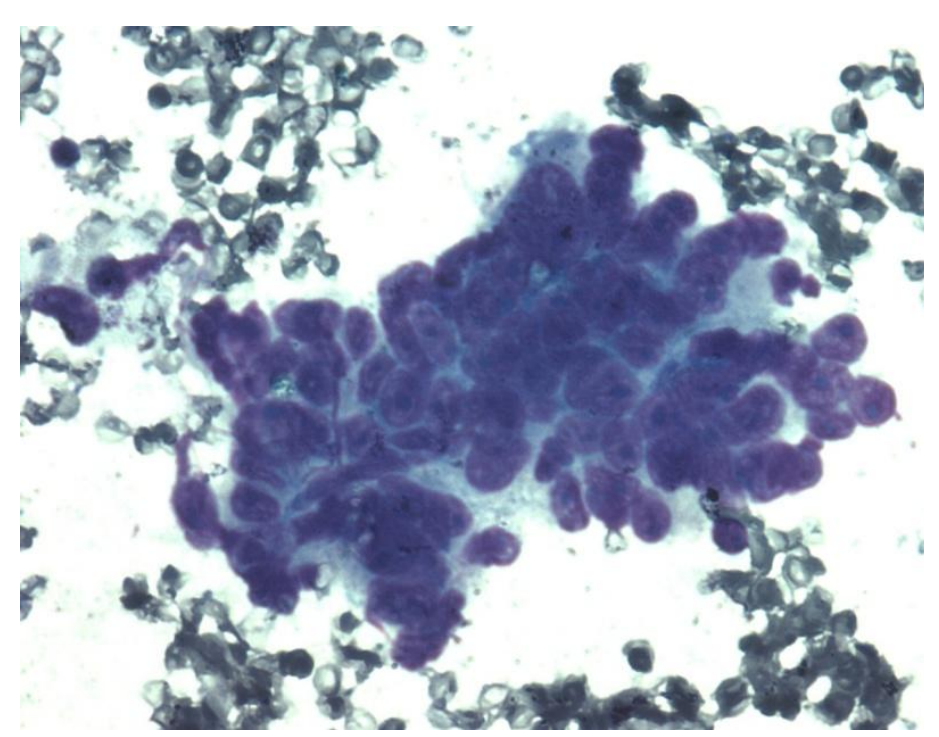

Fig. 8. A case of metastatic deposits from adenocarcinoma showing atypical cells forming acini in a hemorrhagic background.

\section{DISCUSSION}

In the diagnosis and management of various hepatic lesion, FNAC plays an important role along with radiological features and biochemical level remains supportive. ${ }^{4}$ It offers accuracy with minimal intervention and without any major complications at a low cost. ${ }^{5}$ Role of FNAC becomes important in diagnosis of liver lesions mainly for diagnosing hepatic malignancies metastatic or primary origin. ${ }^{6}$ In addition to other advantage of FNAC, it takes very less time thus can be performed on outdoor basis and requires no hospitalization. $^{7}$

In our study, patients age ranged from 15-90 years with maximum number of patients were in sixth decade. There was male predominance $(56.84 \%)$ over females (43.16\%). Same observation of male predominance was found in other studies. Ali SR et $\mathrm{al}^{8}$ studied a total of 138 cases of FNA liver smears during three years. Age group ranged from 22 to 85 yrs with maximum cases in the range of 40-55 yrs. In the study by Gatphoh ED et al, ${ }^{9}$ out of the 202 patients with liver diseases, 138 $(68.3 \%)$ were males and $64(31.6 \%)$ females. Swamy CMS et al $^{10}$ studied a total of 72 cases with patients' age ranged from eight months to 90 years out of which 48 were males $(66.67 \%)$ and $24(33.33 \%)$ were females.

Cytomorphologically liver lesions were categorized in to malignant $(58.95 \%)$, benign $(11.58 \%)$, and non-conclusive $(21.05 \%)$ in our study with a total of $79 \%$ diagnostic yield. Study of Ali SR et $\mathrm{al}^{8}(\mathrm{n}=138)$ showed 122 conclusive results $(88.4 \%)$ in which 17 cases $(12 \%)$ were 
benign, and 95 (69\%) were malignant. Rasania A et $\mathrm{al}^{11}$ studied FNA smears of liver lesion in 90 cases. It was conclusive in 84 cases (99.33\%). Out of total aspirates, $23.3 \%$ (21 cases) were benign, $67.7 \%$ (61) were malignant, $6.6 \%$ (6) were nonrepresentative, while $2.2 \%$ (2) were suspicious of malignancy. In study by Swamy CMS et al ${ }^{10}$ $(\mathrm{n}=72)$ diagnosis was rendered in $71 / 72$ cases. Cytomorphologically, liver lesions were categorized into non-neoplastic lesions $(30.56 \%)$ neoplastic lesions $(68.06 \%)$ and inadequate for interpretation (1.38\%).

In our study, benign lesions $(\mathrm{n}=11,11.58 \%)$ were cirrhosis liver (5), fatty liver (4), and pyogenic liver abcess (2). No benign neoplasm was reported during the study. Out of total 17 benign lesions in study of Ali SR et al, ${ }^{8} 5$ were benign cytic lesions, 4 infectious, 4 regenerative nodules, 3 hepatic adenomas and one hemangioma. Benign conditions $(\mathrm{n}=21,23.33 \%)$ were liver abscess (7.3\%), inflammatory (4.8\%), cirrhotic/ parenchymal disease of liver (2.4\%) and regenerative nodule $(1.2 \%)$ in study by Rasania et al. ${ }^{11}$ The cytological diagnosis in $102(50.4 \%)$ was nonneoplastic inflammatory and parenchymal disease of the liver out of 202 cases in study of Gatphoh ED et al. ${ }^{9}$ Swamy CMS et al ${ }^{10}(n=72)$ observed a total of 22 non-neoplastic lesions including pyogenic liver abscess (4), amoebic liver abscess (3), cirrhosis (6), and fatty liver (1) and granulomatous hepatitis (3)

Out of 56 malignant cases, $51(91.07 \%)$ were of metastatic deposits. Five cases $(8.93 \%)$ were of primary origin which all are hepatocellular carcinoma (HCC). Cytologically the smears of HCC were hypercellular with transgression of the vessels in the cell clusters, atypical bare nuclei, large polygonal cells, increased nuclear cytoplasmic ratio with central round nucleus having macro nucleoli and intranuclear inclusions. Metastatic deposits constituted poorly differentiated carcinoma 15 (26.79\%), adenocarcinoma 25 (44.65\%), squamous cell carcinoma $4(7.15 \%)$, renal cell carcinoma 2 (3.57\%), mesenchymal tumor $1(1.78 \%)$, mucinous carcinoma $1(1.78 \%)$, round cell tumor $1(1.78 \%)$ and small cell carcinoma 2 (3.57). Primary site for liver metastasis was diagnosed in 33 cases $(64.7 \%)$ and unknown in 18 cases (35.3\%). Primary origin included gall bladder (10), GIT (6), pancreas (6), breast (5), bronchogenic (3), RCC (2) and mesenchymal (1). Ali SR et $\mathrm{al}^{8}(\mathrm{n}=122)$ studied 95 malignant cases with $40(42 \%)$ were primary of the liver and $55(58 \%)$ were secondaries including metastatic adenocarcinoma, squamous cell carcinoma, melanoma, neuroendocrine, small cell carcinoma and spindle cell neoplasm. Metastatic tumors were the most common among the malignant liver lesions and constituted $70.4 \%$ in study of Rasania A et al. ${ }^{11}$ The different types of metastatic lesions were, carcinoma $2 \%$, while the round cell neoplasm, ovarian, renal \& small cell carcinoma lung, each were $2.3 \%$. The commonest primary hepatic lesion was hepatocellular carcinoma (HCC) (26.2\%).

In the study by Gatphoh ED et al, ${ }^{9}$ there were 100 (49.5\%) patients with cytological diagnosis of malignant disease in the liver. The commonest malignant disease in the liver was metastatic carcinoma (64\%). Primary HCC was observed in $31(31.0 \%)$ patients and $4(4 \%)$ were Non Hodgkin's lymphoma. One patient had hepatoblastoma. The primaries of the metastatic carcinomas were from GIT, lungs, breast and kidneys. In study of Swamy CMS et al, ${ }^{10} \mathrm{HCC}$ was the most common neoplastic liver lesion (26, $36.12 \%$ ) out of 49 malignant cases. Metastatic carcinoma in liver $(n=22)$ were diagnosed with adenocarcinoma $(14,19.45 \%$, renal cell carcinoma (1), squamous cell carcinoma (1), lymphoma (1) melanoma (1) and poory differentiated carcinoma (4).

\section{CONCLUSION}

USG-guided FNAC is a safe, quick, cost effective and easily accessible procedure to diagnose the liver lesions at an early stage. It offers accuracy without any major complications that can be done on OPD basis. 
SOURCE OF FUNDING- None.

CONFLICT OF INTEREST- All authors state

that there are no conflicts of interests.

\section{REFERENCES}

1. Kuo FY, Chen WJ, Lu SN, Wang JH, Eng HL. Fine needle aspiration cytodiagnosis of liver tumors. Acta Cytol. 2004;48:1428.

2. Shah A, Jan GM. Fine needle aspiration cytology of liver. A study of 518 cases. J Cytol 2002;19:139-43.

3. B.Bastian. Liver and Spleen. In: Orell SR, Sterret GF, Whitaker D, editors. Fine needle aspiration cytology. $5^{\text {th }}$ ed. New Delhi: Churchill Livingstone; 2005. pp. 271-296.

4. Sattar A, Khan AM, Anjum S, Naqvi A. Role of ultrasound guided fine needle aspiration cytology in diagnosis of space occupying lesions of liver. J Ayub Med Coll Abbottabad 2014;26:334-6.

5. Whitlach S, Nunez C, Pitlik DA. Fine needle aspiration of the liver. A study of 102 consecutive cases. Acta Cytol 1984;28:719-25.

6. Yousaf NW, Jafri S, Masood G, Malik SA. The diagnostic role of fine needle aspiration cytology of liver in malignant focal mass lesions: A cytological correlation. JCPSP 2000;10:109-12.

7. Roy M, Bhattacharya A, Gupta DS, Sanyal S. Fallacies of fine needle aspiration cytology of surgical lesions of liver. J Ind Med Assoc 1994;92:285-87.

8. Ali SR, Jayabackthan L, Rahim S, Sharel MB, Prasad K, Hegdekatte N. Role of fi ne needle aspiration cytology in the diagnosis of hepatic lesions. Muller J Med Sci Res 2015;6:125-8.

9. Gatphoh ED, Gaytri S, Babina S, Singh AM. Fine needle aspiration of liver: a study of 202 cases. Indian J Med Sci.2003;57:22-5.

10. Swami M, Arathi CA, Kodandaswamy CR. Value of Value of ultrasonography guided fine needle aspiration cytology in the investigative sequence of hepatic lesions with an emphasis on hepatocellular carcinoma.J Cytol. 2011;28:178-84.

11. Rasania A, Pandey CL, Joshi N. Evaluation of FNAC in diagnosis of hepatic lesion. J Cytol. 2007;24:51-4. 